\title{
Effect of stacking sequence on the flexural and fracture properties of carbon/basalt/epoxy hybrid composites
}

\author{
Jae Il Lim¹, Kyong Yop Rhee ${ }^{1, \star}$, Hyun Ju Kim² and Dong Ho Jung ${ }^{2}$ \\ ${ }^{1}$ Department of Mechanical Engineering, College of Engineering, Kyung Hee University, Yongin 446-701, Korea \\ ${ }^{2}$ Maritime and Ocean Engineering Research Institute, Korea Institute of Ocean Science and Technology, Daejeon 305-600, Korea
}

\author{
Article Info \\ Received 16 January 2014 \\ Accepted 3 March 2014 \\ *Corresponding Author \\ E-mail: rheeky@khu.ac.kr \\ Tel: $+82-31-201-2565$
}

\section{Open Access}

DOI: http://dx.doi.org/

10.5714/CL.2014.15.2.125

This is an Open Access article distributed under the terms of the Creative Commons Attribution Non-Commercial License (http://creativecommons.org/licenses/ by-nc/3.0/) which permits unrestricted non-commercial use, distribution, and reproduction in any medium, provided the original work is properly cited.

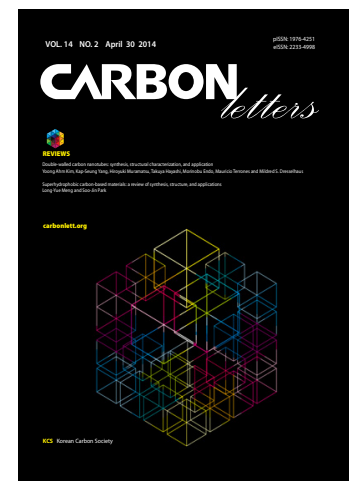

http://carbonlett.org

pISSN: $1976-4251$

elSSN: 2233-4998

Copyright $\odot$ Korean Carbon Society

\begin{abstract}
In this study, the effect of stacking sequence on the flexural and fracture properties of carbon/ basalt/epoxy hybrid composites was investigated. Two types of carbon/basalt/epoxy hybrid composites with a sandwich form were fabricated: basalt skin-carbon core (BSCC) composites and carbon skin-basalt core (CSBC) composites. Fracture tests were conducted and the fracture surfaces of the carbon/basalt/epoxy hybrid composites were then examined using scanning electron microscopy (SEM). The results showed that the flexural strength and flexural modulus of the CSBC specimen respectively were $\sim 32 \%$ and $\sim 245 \%$ greater than those of the BSCC specimen. However, the interlaminar fracture toughness of the CSBC specimen was $\sim 10 \%$ smaller than that of the BSCC specimen. SEM results on the fracture surface showed that matrix cracking is a dominant fracture mechanism for the CSBC specimen while interfacial debonding between fibers and epoxy resin is a dominant fracture process for the BSCC specimen.
\end{abstract}

Key words: hybrid, basalt fiber, carbon fiber, flexural, fracture toughness

\section{Introduction}

It is known that hybrid composites that consist of two or more fibers in a single matrix have unusual properties compared to conventional single fiber reinforced composites. Accordingly, many studies have been performed to investigate the mechanical properties of hybrid composites [1-4]. For instance, Dong et al. [5] investigated the flexural and tensile properties of glass/carbon hybrid composites and Almeida et al. [6] studied the hybridization effect on mechanical properties of curaua/glass hybrid composites by conducting flexural, tensile, and short beam tests. Naik et al. [7] investigated impact behavior and post-impact compressive characteristics of glass-carbon/epoxy hybrid composites with alternate stacking sequences. Their results showed that hybrid composites are less notch sensitive compared to only-carbon or only-glass composites. Pandya et al. [8] studied hybrid composites made of carbon and glass woven fabrics under quasi-static loading. They reported that the hybrid composites with glass fabric layers in the exterior and carbon fabric layers in the interior showed higher tensile strength and ultimate tensile strain than composites with carbon fabric layers in the exterior and glass fabric layers in the interior.

In recent years, basalt fiber has received increasing attention as a substitute for glass fiber on the basis of its ecologically benign and superior mechanical properties. Basalt fiber, which is made from basalt rock, has superior properties relative to glass fiber such as high tensile strength $(\sim 4800 \mathrm{MPa})$, thermal performance $\left(-259^{\circ} \mathrm{C}\right.$ to $\left.960^{\circ} \mathrm{C}\right)$, and chemical resistance and it also considerably more economical carbon fiber. For this reason, basalt fiber is widely used in various industries and many studies have been carried out to understand the mechanical behavior of basalt fiber reinforced composites [9-12]. However, few studies have been made to investigate the mechanical properties of basalt/carbon hybrid composites $[13,14]$. In particular, no research results on the fracture behavior of basalt/carbon hybrid 
composites have been reported to date.

In this study, the effect of stacking sequence on the flexural and fracture properties of carbon/basalt/epoxy hybrid composites was investigated. For this purpose, three-point flexural tests and mode I interlaminar fracture tests were conducted using basalt skin-carbon core (BSCC) composites and carbon skin-basalt core (CSBC) composites. Following fracture tests, the fracture surfaces of both composites were examined using a scanning electron microscope (SEM) to investigate the fracture mechanisms depending on the stacking sequence.

\section{Experimental}

Woven type carbon fibers (CF332NON, Hcarbon, Korea) and basalt fibers (EcoB4-F260, Secotech, Korea) were used as reinforcing materials. The epoxy used was diglycidyl ether of bisphenol A (YD-115, Kukdo Chemical, Korea), and the curing agent was polyamidoamine (G-A0533, Kukdo Chemical). Eight plies of basalt and carbon fabrics with two different stacking sequences were stacked by the hand lay-up method. The stacking sequences used were [carbon/carbon/basalt/basalt] and [basalt/ basalt/carbon/carbon] $]_{s}$. In this study, the composites with [carbon/ carbon/basalt/basalt $]_{\mathrm{s}}$ and $[\text { basalt/basalt/carbon/carbon }]_{\mathrm{s}}$ stacking sequences are denoted as CSBC and BSCC, respectively. The stacked CSBC and BSCC specimens were impregnated with a matrix made of epoxy resin mixed with curing agent $(2: 1 \mathrm{v} / \mathrm{v})$ and then cured in a hot press at $15 \mathrm{MPa}$ and $80^{\circ} \mathrm{C}$ for $2 \mathrm{~h}$.

Flexural tests were performed according to the ASTM D-790 standard in a three-point bending mode at a cross-head rate of $0.5 \mathrm{~mm} / \mathrm{min}$ using $130 \times 12.7 \times 1.6 \mathrm{~mm}^{3} \mathrm{CSBC}$ and BSCC specimens. Mode I interlaminar fracture toughness tests were performed using double-cantilever beam (DCB) CSBC and BSCC specimens according to the ASTM D5528-01 standard. For DCB fracture specimens (width $25 \mathrm{~mm}$ and length $200 \mathrm{~mm}$ ), an initial crack was made by inserting a $20 \mathrm{~mm}$ Kapton film (thickness: $13 \mu \mathrm{m}$ ) between the fourth and fifth plies. In order to measure crack extension, one side of the DCB specimens was coated with a correction fluid and marked with thin vertical lines. The cross-head speed was set at $2 \mathrm{~mm} / \mathrm{min}$. The crack length, displacement, and fracture load values were measured to calculate fracture toughness. Four flexural and fracture tests, respectively, were performed to ensure reliability of the test results. Fig. 1 shows schematic diagrams of the CSBC and BSCC DCB specimens and the test equipment.

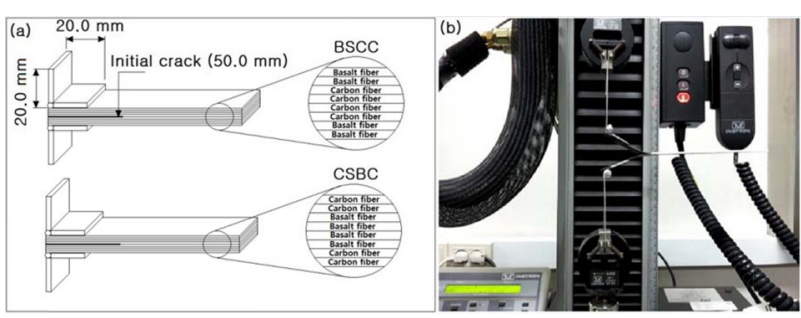

Fig. 1. Schematic diagrams of basalt skin-carbon core (BSCC) and carbon skin-basalt core (CSBC) double-cantilever beam specimens and the test equipment

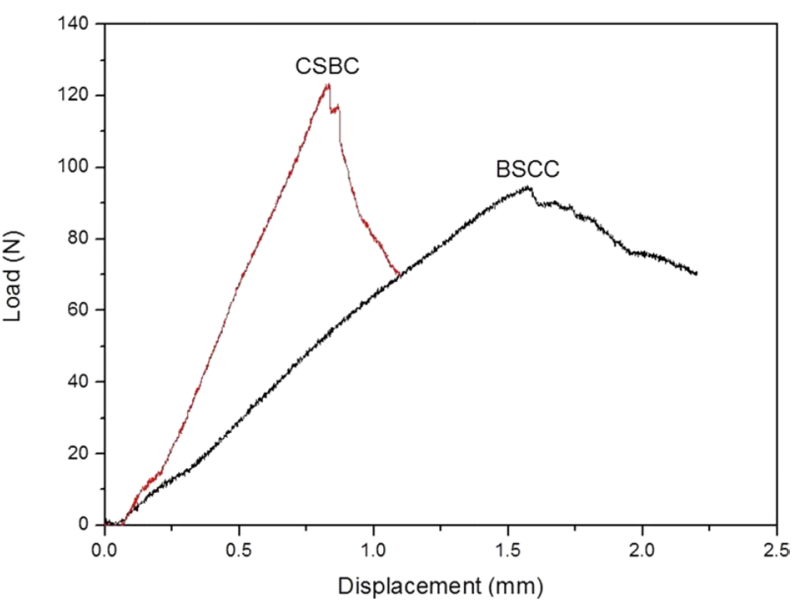

Fig. 2. Flexural load-displacement curves of basalt skin-carbon core (BSCC) and carbon skin-basalt core (CSBC) composites.
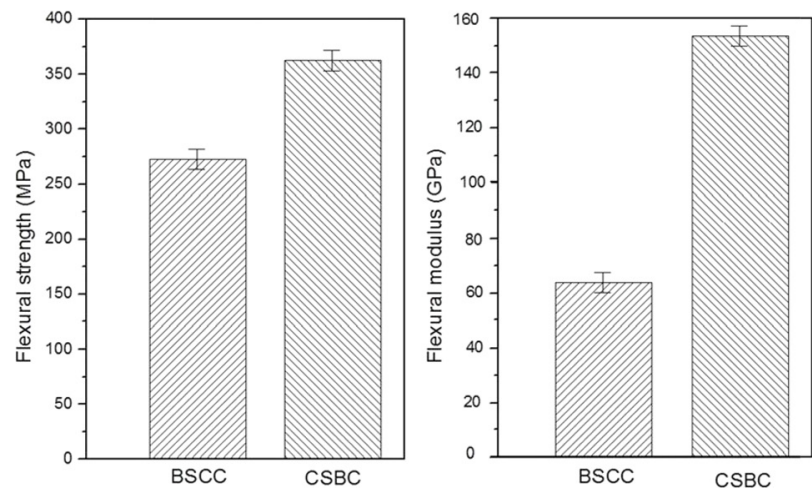

Fig. 3. Comparison of flexural strength and flexural modulus of basalt skin-carbon core (BSCC) and carbon skin-basalt core (CSBC) composites.

\section{Results and Discussion}

Fig. 2 shows the flexural load-displacement curves of the CSBC and BSCC hybrid composites. It can be seen in the figure that both composites exhibited almost linear elastic behavior before the reaching the maximum applied load. It also can be seen in the figure that the CSBC composites, which have carbon fabrics at the skin, displayed stiffer behavior than the BSCC composites, which have basalt fabrics at the skin. The figure also shows that the flexural strength and the flexural modulus of the carbon/basalt/epoxy hybrid composites are influenced by the stacking sequence of the basalt and carbon fabrics. Fig. 3 compares the flexural strength and the flexural modulus of the CSBC composites with those of the BSCC composites. The flexural strength and the flexural modulus were determined using the following equations:

$$
\begin{aligned}
& \text { Flexural strength }\left(\sigma_{\mathrm{f}}\right)=\frac{3 P_{\max } L}{2 b h^{2}} \\
& \text { Flexural modulus }\left(\mathrm{E}_{\mathrm{f}}\right)=\frac{P_{\max } L^{3}}{4 b h^{3} d}
\end{aligned}
$$




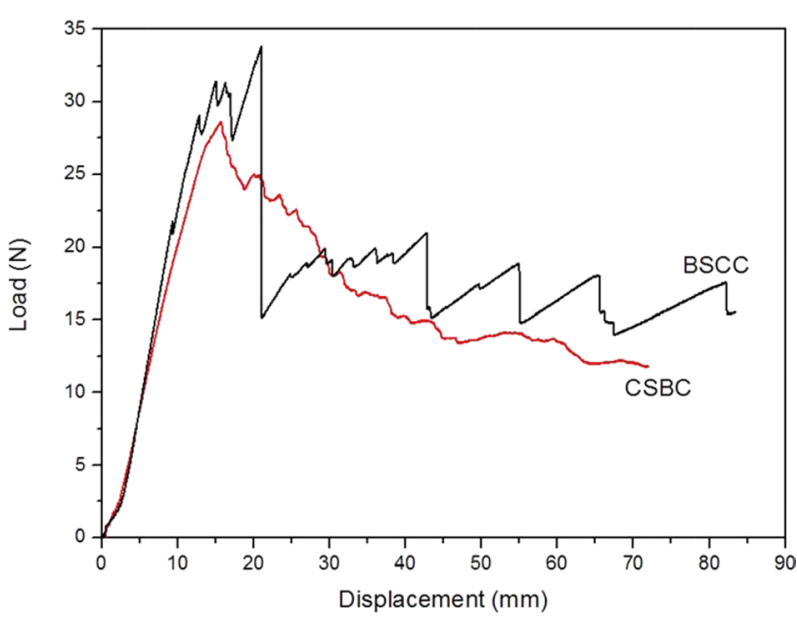

Fig. 4. Mode I load-displacement curves of basalt skin-carbon core (BSCC) and carbon skin-basalt core (CSBC) composites.

In the above equations, " $P_{\max }$ ", " $L ", " b "$, " $h$ ", and " $d$ " represent the maximum load encountered before failure, the support span, the width of the specimen, the depth of the specimen, and the maximum deflection before failure. As shown in the figure, the flexural strength of the CSBC composites was $\sim 32 \%$ greater than that of the BSCC composites. Also, the flexural modulus of the CSBC composites was $\sim 245 \%$ greater than that of the BSCC composites. This is attributed to the maximum tensile and compressive stresses occurring at the top and bottom (skin) regions of the sandwich form specimen when the specimen is under flexural loading. Therefore, strengthening the skin parts is a more effective approach than strengthening the core parts of the sandwich form when flexural loading is applied to the sandwich form structure. This explains why the CSBC composites, which have superior tensile properties of skin parts compared to those of the BSCC composites, produced better flexural strength and modulus.

The critical energy release rate, which is the fracture toughness, indicates the crack resistant force at the moment a new surface is created at a crack tip. Mode I fracture toughness, $G_{I c}$, can be determined by various methods. In this study, $G_{I c}$ was determined using a modified beam theory method:

$$
\mathrm{G}_{\mathrm{IC}}=\frac{3 P \delta}{2 b(a+|\Delta|)}
$$

In the equation, " $P$ ", " $\delta$ ", " $b$ ", " $a$ ", and " $\Delta$ " denote the load at which a crack propagates, displacement, width of the specimen, crack length, and a correction factor for rotation at the crack tip. The correction factor, " $\Delta$ ", was determined experimentally by plotting the cubic root of compliance versus the crack length [15]. Fig. 4 compares typical mode I fracture load-displacement curves along with the crack propagation for CSBC and BSCC composites. As shown in the figure, the load linearly increased with displacement to the maximum load without crack extension for both composites. It also can be seen in the figure that the load varied in a saw-tooth manner with displacement for further crack propagation. The saw-tooth variation of load with displacement occurs due to unstable crack propagation (slip-stick behavior) and similar research results regarding carbon/Kevlar/ epoxy composites were reported by Kim et al. [16]. Notable in

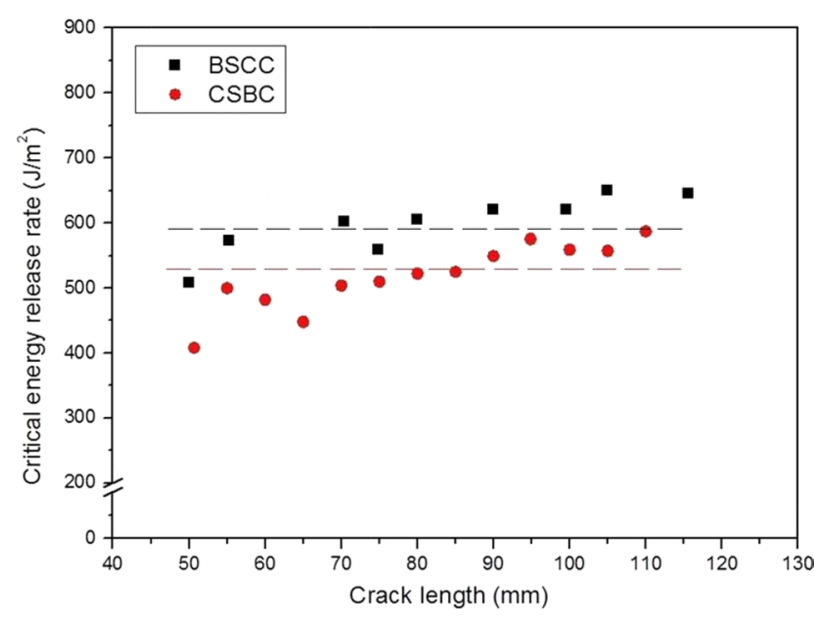

Fig. 5. Comparison of critical energy release rate, $G_{k \text {, }}$ of basalt skincarbon core (BSCC) and carbon skin-basalt core (CSBC) composites.
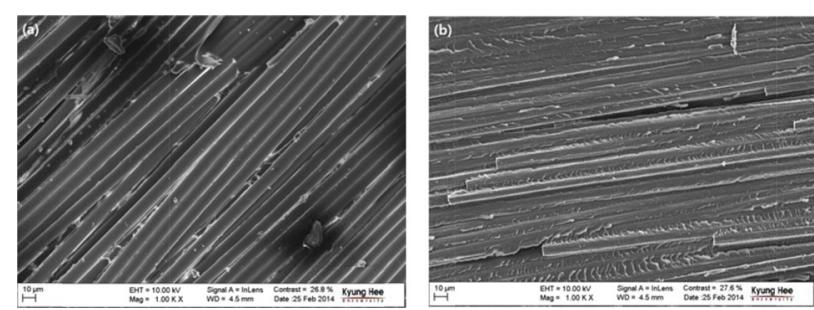

Fig. 6. Scanning electron microscope images of fracture surfaces of basalt skin-carbon core and carbon skin-basalt core composites.

Fig. 4 is that the fracture load of the BSCC composites is greater than that of the CSBC composites at the same crack length, where the flexural strength of the BSCC composites is smaller than that of the CSBC composites. Fig. 5 shows the variation of $G_{I c}$ as a function of crack length (R curve) for both composites. As shown in the figure, the values of $G_{I c}$ vary in a limited range as the crack length increases for both composites. It can also be seen that the $G_{I c}$ values of the BSCC composites were greater than those of the CSBC composites with the same crack length. The average $G_{I c}$ value of the CSBC composites was $530 \mathrm{~J} / \mathrm{m}^{2}$ but it increased by $\sim 10 \%$ to $583 \mathrm{~J} / \mathrm{m}^{2}$ after changing the stacking sequence to BSCC composites.

A SEM analysis was conducted on the fracture surface of $\mathrm{CSBC}$ and BSCC composites to investigate the fracture mechanism of carbon/basalt/epoxy hybrid composites due to stacking sequence. Fig. 6a shows the fracture surface of the BSCC composites, and Fig. $6 \mathrm{~b}$ shows the fracture surface of the CSBC composites. For the BSCC composites, as shown in Fig. 6a, the carbon fibers were relatively clean, showing that carbon fibers were removed from the epoxy matrix. Compared to the BSCC composites, some basalt fibers were fractured, whereas they sufficiently adhered to the epoxy matrix in the CSBC composites (Fig. 6b). It also can be seen that the epoxy matrix was fractured in a hackle pattern. This indicates that matrix cracking and fiber breakage are dominant fracture mechanisms for CSBC composites while debonding between fibers and the matrix plays an important role in the BSCC composites. 


\section{Conclusions}

In this study, the effect of stacking sequence on the flexural and fracture properties of carbon/basalt/epoxy hybrid composites was investigated through flexural and mode I interlaminar fracture tests. The conclusions obtained from this study were as follows. The flexural strength and flexural modulus of the CSBC composites were $\sim 32 \%$ and $\sim 245 \%$ greater than those of the BSCC composites, respectively. On the other hand, the fracture toughness of the CSBC composites was $\sim 10 \%$ smaller than that of the BSCC composites. Fiber breakage and matrix cracking were the dominant fracture mechanisms for the CSBC composites and debonding between fibers and the matrix was the dominant fracture mechanism for the BSCC composites.

\section{Acknowledgements}

This work was financially supported by the National R\&D project "Development of Energy Utilization Technology of Deep Sea Water Resources" supported by the Ministry of Oceans and Fisheries of the Republic of Korea.

\section{References}

[1] Zhang J, Chaisombat K, He S, Wang CH. Hybrid composite laminates reinforced with glass/carbon woven fabrics for lightweight load bearing structures. Mater Des, 36, 75 (2012). http://dx.doi. org/10.1016/j.matdes.2011.11.006.

[2] Dai G, Mishnaevsky, L, Jr. Fatigue of hybrid glass/carbon composites: 3D computational studies. Compos Sci Technol, 94, 71 (2014). http://dx.doi.org/10.1016/j.compscitech.2014.01.014.

[3] Czél G, Wisnom MR. Demonstration of pseudo-ductility in high performance glass/epoxy composites by hybridisation with thinply carbon prepreg. Composites A, 52, 23 (2013). http://dx.doi. org/10.1016/j.compositesa.2013.04.006.

[4] Guermazi N, Haddar N, Elleuch K, Ayedi HF. Investigations on the fabrication and the characterization of glass/epoxy, carbon/epoxy and hybrid composites used in the reinforcement and the repair of aeronautic structures. Mater Des, 56, 714 (2014). http://dx.doi. org/10.1016/j.matdes.2013.11.043.

[5] Dong C, Sudarisman, Davies I. Flexural properties of E glass and
TR50S carbon fiber reinforced epoxy hybrid composites. J Mater Eng Perform, 22, 41 (2013). http://dx.doi.org/10.1007/s11665012-0247-7.

[6] Almeida JHS, Jr., Amico SC, Botelho EC, Amado FDR. Hybridization effect on the mechanical properties of curaua/glass fiber composites. Composites B, 55, 492 (2013). http://dx.doi.org/10.1016/j. compositesb.2013.07.014.

[7] Naik NK, Ramasimha R, Arya H, Prabhu SV, ShamaRao N. Impact response and damage tolerance characteristics of glass-carbon/epoxy hybrid composite plates. Composites B, 32, 565 (2001). http:// dx.doi.org/10.1016/S1359-8368(01)00036-1.

[8] Pandya KS, Veerraju C, Naik NK. Hybrid composites made of carbon and glass woven fabrics under quasi-static loading. Mater Des, 32, 4094 (2011). http://dx.doi.org/10.1016/j.matdes.2011.03.003.

[9] Banibayat P, Patnaik A. Variability of mechanical properties of basalt fiber reinforced polymer bars manufactured by wet-layup method. Mater Des, 56, 898 (2014). http://dx.doi.org/10.1016/j. matdes.2013.11.081.

[10] Borhan TM. Properties of glass concrete reinforced with short basalt fibre. Mater Des, 42, 265 (2012). http://dx.doi.org/10.1016/j. matdes.2012.05.062.

[11] Kim MT, Kim MH, Rhee KY, Park SJ. Study on an oxygen plasma treatment of a basalt fiber and its effect on the interlaminar fracture property of basalt/epoxy woven composites. Composites B, 42 , 499 (2011). http://dx.doi.org/10.1016/j.compositesb.2010.12.001.

[12] Kim MT, Rhee KY, Kim HJ, Jung DH. Effect of moisture absorption on the flexural properties of basalt/CNT/epoxy composites. Carbon Lett, 13, 187 (2012). http://dx.doi.org/10.5714/ CL.2012.13.3.187.

[13] Wang X, Hu B, Feng Y, Liang F, Mo J, Xiong J, Qiu Y. Low velocity impact properties of 3D woven basalt/aramid hybrid composites. Compos Sci Technol, 68, 444 (2008). http://dx.doi.org/10.1016/j. compscitech.2007.06.016.

[14] Fiore V, Di Bella G, Valenza A. Glass-basalt/epoxy hybrid composites for marine applications. Mater Des, 32, 2091 (2011). http:// dx.doi.org/10.1016/j.matdes.2010.11.043.

[15] Shokrieh MM, Heidari-Rarani M, Ayatollahi MR. Delamination R-curve as a material property of unidirectional glass/epoxy composites. Mater Des, 34, 211 (2012). http://dx.doi.org/10.1016/j. matdes.2011.08.006.

[16] Kim SC, Kim JS, Yoon HJ. Experimental and numerical investigations of mode I delamination behaviors of woven fabric composites with carbon, Kevlar and their hybrid fibers. Int J Precis Eng Manuf, 12, 321 (2011). http://dx.doi.org/10.1007/s12541-011-0042-7. 